\title{
ALGUNAS ANOTACIONES AL LIBRO DE FAMILIA DEL PROYECTO DE CODIGO CIVIL
}

Róger Rodriguez Iturri

\begin{abstract}
A próposito del texto de las Secciones Normas Básicas. Impedimentos, Celebración del Matrimonio, Prueba del Matrimonio, Invalidez del Matrimonio, Deberes y Derechos que nacen del Matrimonio, Separación de Cuerpos, y Divorcio.
\end{abstract}

Creo conveniente formular algunos comentarios a la ponencia de Libro de Familia, para el nuevo Código Civil nacional.

No se trata de una reflexión doctrinaria, sino más bien de algunas precisiones en torno a algunos aspectos hallados en las Secciones Normas Básicas, Impedimentos, Celebración del Matrimonio. Prueba del Matrimonio. Invalidez del Matrimonio, Deberes y Derechos que nacen del Matrimonio, Separación de Cuerpos y Divorcio, Secciones de las que me ocupo ahora.

Deseo referirme a ello, no sin antes destacar con decisión la alta calidad de la ponencia formulada por el señor doctor Héctor Cornejo Chávez, reconocido como el más destacado académico de Derecho de Familia, en nuestro medio.

He aqui algunos comentarios: 
La ponencia dice:

"Art. 286. - El matrimonio produce parentesco de afinidad "entre cada uno de los cónyuges y los parientes consanguíneos "del otro. Cada cónyuge se halla, por afinidad, en igual "línea y grado de parentesco con ellos que lo está el otro "por consanguinidad".

(El artículo continua con un segundo párrafo, intrascendente para este análisis).

Se sugiere modificar la redacción de la segunda parte del primer párrafo del artículo. Se desea clarificar la norma. Para este fin se considera útil el Art. 120 del Código de Familia de Cuba, promulgada por Ley 1289 de 14 de febrero de 1975.

Se juzga que la expresión "cada cónyuge se halla, por afinidad, en igual línea y grado de parentesco con ellos, que lo está el otro por consanguinidad", puede ser sustituida por una expresión sintética y precisa - la cubana- que regla asi: "los parientes consanguíneos de un cónyuge lo son del otro, por afinidad, en la misma linea y grado".

Entonces el Art. 286 del Proyecto asumiria el siguiente texto:

"El matrimonio produce parentesco de afinidad entre cada uno "de los cónyuges y los parientes consanguineos del otro. Los "parientes consanguíneos de un cónyuge lo son del otro por "afinidad, en la misma linea y grado.

"La afinidad en linea recta no acaba por la disolución del "matrimonio que la produzca. Subsiste la afinidad en el se"gundo grado de la linea colateral en caso de divorcio y "mientras el ex cónyuge viva".

\section{IMPEDIMENTOS}

En la Sección Segunda del Título Primero, el ponente ha desarrollado la teoria de los impedimentos matrimoniales. En el rico contenido, pueden introducirse algunas ideas. 
Sugerimos clasificar los impedimentos en cuatro tipos:
a) Fisicos;
b) Volitivos (ausencia de voluntad);
c) Por razón de parentesco;
d) Morales.

Tal distribución contribuye a una adecuada interpretación.

Dentro de este orden de ideas, un nuevo Art. 290 en el Proyecto, podria tener el siguiente contenido:

"Por ausencia de aptitud física no pueden contraer matrimonio "los que adolecieren de enfermedad crónica, contagiosa y trans"misible por herencia, o de vicio que constituya peligro para "la prole".

El impedimento volitivo, que tantas veces tiene ligazón con el impedimento físico, constituiria un nuevo Art. 291 en el Proyecto, con el siguiente tenor:

"Por ausencia de aptitud volitiva y física no pueden con"traer matrimonio:

"1. Los impúberes. La pubertad legal se ancanza a los 18

". años dee edad. El juez podrá dispensar el impedimento

“ por motivos graves siempre que el varón tenga 16 años

" cumplidos y la mujer 14;

"2. Los que padecieren crónicamente de enfermedad men-

" tal aunque tengan intervalos lúcidos;

"3. Los sordomudos, ciegos-sordos y mudos-ciegos, que no "supieren expresar su voluntad de manera indubitable".

Por similitud se incluye en el Inc. 3; los casos del ciego-sordo y mudo-ciego.

En nuevo Art. 292 para el Proyecto, se encuadraria el impedimento matrimonal por razón del parentesco. E1 artículo asumiria la siguiente redacción: 
"Por razón de parentesco no pueden contraer matrimonio:

"1. Los casados.

"2. Los consanguineos en linea recta.

" El fallo que condena el pago de alimentos a favor del

“ hijo extramatrimonial no reconocido ni declarado judi-

" cialmente produce también el impedimento a que se

. refiere este inciso.

“3. Los consanguineos en la linea colateral dentro del se-

" gundo y tercer grado. Tratándose del tercer grado el

“ impedimento podrá ser dispensado por el juez cuando

" existan motivos.

“4. Los afines en linea recta.

“5. Los afines en el segundo grado de la linea colateral

". cuando el matrimonio que produjo la afinidad se disol-

“ vió por divorcio y el ex-cónyuge vive.

“6. El adoptante, el adoptado y sus familiares en las lineas

“ dentro de los grados señalados para la consanguini-

". dad y la afinidad en los incisos precedentes".

Un nuevo Art. 293, permitiria al Proyecto, siempre de manera ordenada, nuclear los casos de impedimento moral.

El precepto puede configurarse asi:

"No pueden contraer matrimonio entre sí:

"1. El condenado como partícipe en el homicidio doloso

“ de uno de los cónyuges con el sobrevivente, ni el pro-

" cesado por esta causa mientras dure el proceso.

"2. Quien rapta con la persona raptada mientras ésta se

" halle en su poder.

“ El impedimento se extiende al caso de retención vio“ lenta".

Hasta aqui se ha realizado una propuesta que en esencia entraña un reordenamiento técnico y coherente que, sin perjuicio de la alta calidad de la ponencia, permite una captación precisa de la teoría de los impedimentos matrimoniales en la ley. Se ha hecho una tipificación legal de la teoria, sobre la base de sus rasgos fisicos, volitivos, parentales y morales. 
Sólo para el caso del matrimonio del raptor, se ha modificado la redacción, a efectos de no dejar duda del sentido jurídico del impedimento (Art. 291, Inc. 7 del Proyecto).

Sin embargo, la doctrina presenta la incontestable vigencia de los matrimoniales ilicitos. En el Proyecto pudo corresponder a ellos una sección propia, pero bien cabe tamblén la posibilidad de presentarlos en este segmento del Libro. El Proyecto sustenta el cuadro de matrimonios ilicitos en el Art. 292 que contiene tres incisos.

Nuestra propuesta tiene la siguiente formulación.

El numeral sería el 294, bajo el siguiente tenor:

"Son matrimonios ilicitos pero válidos:

“1. El del tutor o el curador con el menor o el incapaz du“ rante el ejercicio del cargo ni antes de que estén ju. dicialmente aprobadas las cuentas de la administra-

. ción, salvo que el padre o la madre de la persona su. jeta a la tutela o curatela hubiese autorizado el matri“ monio por testamento o escritura pública. El tutor o “ curador que infringiere la prohibición perderá la retri“ bución que le habría correspondido, sin perjuicio de la “ responsabilidad que le corresponde por el desempeño “ del cargo.

"2. El del viudo y la viuda, que no acredita haber hecho “. inventario judicial con intervención del Ministerio Públi" co, de los bienes pertenecientes a sus hijos que esté “. administrando o sin que preceda declaración jurada de ". que no tiene hijos bajo su patria potestad o de que los ". hijos no tienen tales bienes.

“ La infracción de esta norma acarrea la pérdida del usu". fructo legal sobre los bienes de dichos hijos. Esta dis" posición es aplicable al cónyuge cuyo matrimonio hu“ biese sido invalidado o disuelto por divorcio, así como " al padre o madre que tenga hijos extramatrimoniales “ bajo su patria potestad.

“3. El de la viuda en tanto no transcurran por lo menos . $\quad 300$ dias de la muerte de su marido, salvo que diere a 
luz. Esta disposición es aplicable a la mujer divorciada, o cuyo matrimonio hubiera sido invalidado.

El juez podrá conceder dispensa del plazo de espera cuando sea imposible, atendidase las circunstancias, que la mujer se halle emabarazada de obra del marido.

" No rige la prohibición tratándose de la mujer divor-

“ ciada cuando el divorcio se hubiera sentenciado por

“ causa del abandono malicioso del hogar durante más

.. de dos años contínuos o por conversión de la separación

. de cuerpos en divorcio por el transcurso de un año.

“ La viuda, la divorciada o la cónyuge cuyo matrimonio

.. hubiese sido invalidado, que contravenga la prohibición

“ contenida en este inciso perderá los bienes que hubiese

“ recibido del marido a titulo gratuito.

“ Es de aplicación a los casos a que se refiere este inciso, la presunción de paternidad respecto del nuevo marido".

De esta manera quedaria explicada en la ley la tipologia de los denominados matrimonios ilícitos, obteniéndose una notoria claridad en su presentación.

Como se aprecia se han respetado los casos sugeridos por el ponente. El del tutor y el curador mantienen el mismo contexto que en la ponencia; otro tanto ocurre con el caso del viudo o viuda que contrae nuevas nupcias sin previo inventario judicial con intervención del Ministerio Público. En cambio para el caso de la viuda, divorciada, o de aquella cuyo matrimonio se invalidó, y que contraen nuevas nupcias sin respetar el plazo que evita la turbatio sanguinis, hemos esparcido la sanción propia más allá de la viuda, que según el Proyecto es la única sancionada.

Apréciese que en esta Sección Segunda del Título Primero, no nos ocupamos del caso mencionado en la ponencia con el numeral 295. Se refiere al matrimonio del menor casado sin consentimiento legal. Tradicionalmente ha sido concebido este caso como matrimonio ilicito. Luego al ocuparnos del matrimonio del impúber, esbozaremos nuestra solución sobre esta materia.

De otro lado, y refiriéndonos al "Consentimiento para el Matrimonio de Menores", en aras de una más adecuada subvisión 
del contenido del Libro de Familia, sobre la base de la tendencia de los Códigos Civiles de 1852 y 1936, nos pronunciamos por una Sección propia.

La propuesta planteada en el Art. 293 nos parece saludable. Más sugerimos que se convierta tal numeral en la Sección Tercera del Capitulo I del Título Primero.

No habiéndose tratado en la ponencia, la parte procesal que se refiere a quién representa al menor ante el Juez de Menores. en ausencia de los representantes legales, podria resolverse con la sugerencia que como párrafo cinco proponemos en este nuevo Art. 295.

El texto queda como sigue:

"Los menores de edad, para contraer matrimonio, necesitan "del consentimiento expreso de sus padres. La discrepancia "entre los padres equivale al consentimiento.

"Por falta, incapacidad absoluta o destitución de la patria "potestad de uno de los padres, bastará el consentimiento "del otro.

"A falta de ambos padres o si ambos fueren absolutamente "incapaces o hubiesen sido destituidos de la patria potestad, "prestarán consentimiento los abuelos y abuelas. En igualdad "de votos contrarios, la discordancia equivalente al consen"timiento.

"A falta de abuelos y abuelas o sin son absolutamente inca"paces o hubiesen sido removidos de la tutela, corresponde "al Juez de Menores otorgar o negar la licencia supletoria. "La misma atribución corresponde al Juez de Menores tra"tándose de menores expósitos, abandonados, o que se en"cuentren bajo la jurisdicción especial del Libro IV, Título "Quinto del Código Penal.

"Los menores cuando carezcan de la representación a que se "refiere este artículo, solicitarán directamente el consenti"miento al Juez de Menores. Este deberá pronunciarse den"tro del quinto día, previa investigación sumaria, y con in"tervención del Ministerio Público. 
"Los hijos extramatrimoniales sólo requieren el consentimiento "del padre o en su caso de los abuelos paternos, cuando a"quél les hubiere reconocido voluntariamente. La misma re"gla se aplica a la madre y a los abuelos de la línea mater "na".

Se observará que excepcionalmente ofrecemos impulso procesar al menor, inspirándonos en el Art. 143 del Código Civil de 1936, principio repetido en el Art. 325, Inc. 1, de la ponencia.

De esta manera se salva un escollo de significación social.

\section{CELEBRACION DEL MATRIMONIO}

Dentro del reordenamiento que estamos sugiriendo en este estudio, la "Celebración del Matrimonio", se ubicaría como la Sección Cuarta, correspondiente al Capitulo I del Titulo Primero. Obviamente la numeración del articulado se iniciaria en el 295.

Los artículos de la ponencia que sugieren alguna inquietud son el 316 y 310 .

E1 Art. 316 se refiere al caso del matrimonio religioso, celebrado con sujeción a los cánones de la Iglesia Católica, el cual produciría efectos civiles si se inscribe en el Registro del Estado Civil.

Hay quien sostiene ya que el matrimonio in extremis, del Art. 120 del Código Civil de 1936, carece de presencia en el novisimo Proyecto. $\mathrm{Y}$ es posible que la redacción del Art. 316 induzca a tal conclusión.

Nosotros no compartimos esta tesis. Creemos que el numeral 316 del Proyecto, si autoriza el matrimonio in extremis. La ponencia dice "el matrimonio religioso, celebrado con sujeción a los cánones de la Iglesia Católica, produce efectos civiles siempre que se inscriba en el Registro del Estado Civil". Y el Canon 1098 del Código Canónico de 1918, sí autorizaba la validez del matrimonio in extremis. Ello implica que un matrimonio in extremis celebrado con sujeción a la ley de la Iglesia, estaria validado 
por la fórmula preceptual que utiliza el Art. 316 de la ponencia. Hay que concluir que si el reciente Código Canónico del 25 de enero de 1983, repite el precepto del Canon 1098, del derogado Código Canónico de 1918, el matrimonio in extremis está autorizado por el Proyecto de Código Civil peruano. Lamentablemente el novisimo Código Canónico no ha sido aún traducido al español.

Para evitar este alambicado proceso interpretativo, tal vez. en un nuevo Art. 317, podria repetirse la fórmula del Art. 120 del Código Civil de 1936 "si alguno de los contrayentes entuviere en inminente peligro de muerte, el matrimonio podrá celebrarse sin observar las formalidades que deben precederle. Este matrimonio se celebrará ante el párroco o cualquier otro sacerdote y no producirá efectos civiles cuando se contraiga entre personas incapaces".

De otro lado, el sistema que se legisla para la celebración del matrimonio es sensiblemente válido para los grupos humanos' organizados en proximidad al Municipio. El Art. 310 de la ponencia se refiere al matrimonio civil celebrado ante la comunidad campesina. Seria conveniente considerar también el caso de las comunidades nativas. Aunque resulta imprescindible tomar con $\lrcorner$ ciencia de cuán profundo es realmente nuestro conocimiento sobre la vida y prácticas de estos grupos humanos.

\section{LA PRUEBA DEL MATRIMONIO}

"La Prueba del Matrimonio" se convertiría en la Sección Quinta del Capítulo I, Título Primero.

Esta sección está compuesta en la ponencia por la arquitectura jurídica, que constituyó "la prueba del matrimonio" en el Código Civil de 1936.

Como quiera que la puesta en vigencia del Proyecto derogará el Código Civil de 1936, nos preguntamos respecto al estado en que quedan tanto los matrimonios religiosos anteriores a 1936, como el reconocimiento de hijos extramatrimoniales inscritos parroquialmente antes del año 1936. Aparentemente hay aqui un va- 
cío legal, salvo que la observación se considere salvada, para el caso de los matrimonios, por el dicho del numeral 316 de la ponencia, que sostiene: "el matrimonio religioso, celebrado con sujeción a los cánones de la Iglesia Católica, produce efectos civiles siempre que se inscriba en el Registro del Estado Civil". Sin embargo tal visión del problema afecia el principio de la retroactividad legal, contemplado en el Art. 187 de la vigente Constitución Politica del Perú.

Seria entonces recomendable tratar este asunto en las disposiciones transitorias, finales, del Proyecto de Código Civil.

La formulación del precepto, podría inspirarse en el tenor del Art. 1827 del Código Civil de 1936:

"Las partidas de los Registros Parroquiales tendrán el mis"mo valor que las partidas de los Registros del Estado Civil, “si se prueba, mediante la certificación respectiva, la inexis"tencia de este Registro en el lugar correspondiente, y siem"pre que el acto se haya inscrito en el Registro Civil.

“Las partidas de los Registros Parroquiales referidas a los "hechos realizados antes de 1936, conservan la eficacia que "les atribuyen las leyes anteriores.

“El reconocimiento de los hijos extramatrimoniales cuyas par"tidas sólo estuvieran extendidas en los Libros Parroquiales, “podrá ser efectuado en estos libros, ante el párroco, con las "formalidades previstas en el capitulo concerniente a "Filia"ción extramatrimonial", siempre que la inscripción se hubie"re realizado antes de 1936 ".

\section{INVALIDEZ DEL MATRIMONIO}

La Sección Quinta, convertida en nuestra sugerencia en Sección Sexta, está referida a la "Invalidez del Matrimonio".

Entre los Arts. 322 al 334, con singular versación, el ponente ha desarrollado la calificación y matices de los denominados matrimonios nulos y anulables. 
Sabemos que la organización juridico-familiar, sobre esta materia, posee una regulación que difiere en parte de la adoptada para el acto juridico.

De acuerdo a la tesis tradicional los actos nulos son inconfirmables, en tanto que, en términos generales, el acto anulable si es confirmable. En esta materia el Derecho de Familia tiene su propio derrotero.

Si analizamos el numeral 322, en sus 9 incisos, podemos apreciar la presentación de matrimonios, que por su naturaleza son auténticamente nulos, $\mathrm{y}$ otros que por mandato de dicho numeral -inspirado en el Código Civil de 1936- no lo son, aún cuando se les presenta bajo el título de "nulos".

Es por ello que con afán clarificador, y auspiciando un entendimiento transparente de esta institución, sugerimos desarrollar la teoria de la invalidez matrimonial, bajo la nomenclatura de matrimonios nulos y anulables pero haciendo un reordenamiento de éstos.

Esta es la propuesta:

"Art. 322.-

"Es nulo el matrimonio:

“1) De los consanguineos o afines en linea recta;

“2) De los afines en segundo grado de la línea colateral

“ cuando el matrimonio anterior se disolvió por divorció

“ y el ex-cónyuge vive;

“3) Del condenado o procesado por el homicidio doloso

.. de uno de los cónyuges con el sobreviviente a que se “ refiere el Art. 293, Inc. 1;

“4) Del celebrado de mala fe por ambos contrayentes ante

“ funcionario incompetente. La acción no podrá ser planteada por los cónyuges".

Quedarian ahi encuadrados los denominados matrimoniales nulos. 
Luego en artículo distinto, cuya numeración debe establecerse en el reordenamiento de los numerales, se trataria el caso de los matrimonios anulables.

Un comentario previo. El caso del matrimonio del impúber y su similitud con el matrimonio del menor casado sin consentimiento del representante legal.

En el Código Civil de 1936 el caso del menor casado sin consentimiento del representante legal, se concibió como matrimonio ilícito. Es decir sujeto a sanción, pero válido. Es el caso del Art. 100.

De distinta manera trata el Art. 143 al impúber. Lo define como el que "... ha contraido matrimonio sin tener la edad requerida por la ley ...", pero en tal caso sí cabe demandar la nulidad matrimonial, salvo las excepciones de acceso a la pubertad y concepción.

El Proyecto de Código Civil sigue la tendencia del Código Civil de 1936.

Trata como matrimonio ilícito, sancionable pero válido, el caso del menor casado sin consentimiento de representantes legales (Art. 295 del Proyecto).

Luego en el Art. 325, el Proyecto refiere el caso del impúber. Es decir de aquél que contrae matrimonio sin tener edad requerida por la ley, y lo hace sujeto de anulabilidad.

Estamos ante casos aproximados, que tienen soluciones distintas.

Una interpretación conceptúa al impúber como aquél menor casado sin licencia judicial. En el otro caso, de matrimonio de menor la falta radicaria en la ausencia de consentimiento del representante legal.

Es innegable que un matrimonio de menor carente de licencia judicial constituye grave trasgresión legal, y agravia la se- 
guridad social. Por ello es entendible la sanción de anulabilidad propuesta. Pero tan grave como ello es el caso del menor casado sin consentimiento de sus padres, abuelos, o representante, es decir de quienes deben decidir por él.

Queremos armonizar una solución común para casos tan aproximados.

El articulo pertinente tendria el siguiente tenor:

"Es anulable el matrimonio:

"Inc. 1.-

"Del menor que se casa sin licencia judicial, pero se confir"ma si el menor ha alcanzado la edad legal o si la mujer hu"biese concebido.

"El mismo principio es aplicable al caso del matrimonio del "menor que se casa sin consentimiento de quien debe darlo. "La anulación puede ser demandada por el menor, por sus "ascendientes sino hubiesen prestado consentimiento para el "matrimonio, y a falta de éstos por el consejo de familia. "Cuando la anulación ha sido obtenida a instancia de los "padres, ascendientes o consejo de familia, los cónyuges al "llegar a la pubertad legal podrán confirmar su matrimonio "ante el juez. La confirmación tendrá efecto retroactivo".

Los otros casos de anulabilidad serian los siguientes:

"Inc. 2.-

"Del enfermo mental, aunque tenga intervalos lúcidos. No "obstante, cuando el enfermo ha recobrado la plenitud de "sus facultades, la acción corresponde exclusivamente a los "cónyuges y caduca si no se interpone durante el periodo "de un año a partir del día en que cesó la incapacidad;

"Inc. 3.-

"Del sordomudo, del ciego-mudo y del sordo-ciego que no "supieren expresar su voluntad de una manera indubitable. "Empero, si ha aprendido a expresarse sin lugar a duda, es "de aplicación lo dispuesto en el segundo párrafo del inciso "anterior; 
"Inc. 4.-

"Del casado. No obstante, si el primer cónyuge del bigamo

"ha fallecido o si el primer matrimonio ha sido invalida"do o disuelto por divorcio, sólo el segundo cónyuge del "bigamo puede demandar la invalidación, siempre que hu-

"biere actuado de buena fe. $\mathrm{La}$ acción caduca sino se inter-" "pone dentro del plazo de un año desde el día en que tuvo "conocimiento del matrimonio anterior.

“Tratándose del nuevo matrimonio contraido por el cónyuge "de un desaparecido sin que se hubiera declarado la muerte "presunta de éste, sólo podrá ser impugnado, mientras dure "el estado de ausencia, por el nuevo cónyuge siempre que "hubiera procedido de buena fe.

"Terminado el estado de desaparición, ninguno podrá im"pugnar el nuevo matrimonio si se ha declarado la muerte "presunta; mas el primer matrimonio recobrará plena validez "y el segundo valdrá en su caso como putativo, si la ausen"cia terminase por el regreso del desaparecido;

"Inc. 5.-

"De los consanguíneos en segundo y tercer grado. El matri"monio se convalida si se obtiene dispensa judicial del pa"rentesco;

"Inc. 6.-

"De quienes lo hubiesen celebrado con prescindencia de los “trámites previstos por la Sección respectiva de este Libro.

"El matrimonio se convalida con efecto retroactivo, si ambos "cónyuges hubiesen actuado de buena fe, y se subsana la "defección de trámite en que se hubiere incurrido.

"Inc. 7.-

"De quien lo contrajo teniendo el impedimento de sanidad a "que se refiere el Art. 290 de la propuesta. La acción sólo "puede ser intentada por el cónyuge del enfermo y caduca "si no se interpone dentro del plazo de un año a partir del "momento en que tuvo conocimiento de la dolencia o el vicio. "Inc. 8.-

"De quien rapta con la persona raptada mientras se halle "en su poder, o del realizado con retención violenta. La ac"ción corresponde a la víctima, y sólo será admisible si se "plantea dentro del plazo de dos años de celebrado el casa"miento. 
"Inc. 9.-

"De quien lo contrario sin hallarse en el pleno ejercicio de "sus facultades mentales por una causa pasajera. La acción' "sólo podrá ser interpuesta por el cónyuge perjudicado den"tro de los dos años de la celebración del casamiento y siem"pre que no haya hecho vida común durante seis meses des"pués de desaparecida la causa;

"Inc. 10.-

"De quien lo contrajo por error sobre la identidad fisica del "otro contrayente o por ignorancia de alguna calidad sus"tancial del mismo que haga insoportable la vida común. Sé "reputan calidades sustanciales la vida deshonrosa, el haber "sido condenado a más de dos años de pena privativa de la "libertad y el estado civil de divorciado;

"Inc. 11.-

"De quien lo contrajo bajo amenaza de un mal grave $e$ in"minente, capaz de producir en el amenazado un estado de "temor sin el cual no lo hubiera contraído.

"El juez apreciará las circunstancias, sobre todo si la ame"naza hubiera sido dirigida contra terceras personas. El sim"ple temor reverencial no anula el matrimonio. La acción co"rresponde al cónyuge perjudicado y sólo puede ser inter"puesta dentro del plazo de dos años de celebrado el casa"miento;

"Inc. 12. -

"De quien adoleciera de impotencia absoluta al tiempo de "celebrarlo. La acción corresponde a ambos cónyuges y está "expedita en tanto subsista la impotencia. No procede la anu"lación si ambos cónyuges son impotentes;

"Inc. 13.

"De quienes, de buena fe en uno o en ambos cónyuges, lo "han contraido ante funcionario incompetente, sin perjuicio "de la responsabilidad administrativa, civil o penal de dicho "funcionario. La acción corresponde únicamente al cónyuge "o cónyuges de buena fe y debe interponerse durante el "año siguiente a la celebración del casamiento".

Apréciese que se ha respetado la redacción del autor de la ponencia, salvo en las propuestas que hacemos de Inc. 6 e Inc. 8 . por considerar que las introducciones contribuyen a una clarificación sobre la materia. 

NIO

Luego en la ponencia aparece el Capítulo II, referido a las Relaciones Personales entre los Cónyuges, el que en Sección Unica trata "Los Deberes y Derechos que nacen del Matrimonio".

Esta Sección, se encuentra informada por los preceptos del Código Civil de 1936, y dirigida a dar cumplimiento a lo preceptuado en el Art. 2, Inc. 2, de la Constitución Política del Perú (79-80). Se trata de afirmar, por ley civil, la igualdad de derechos y deberes del hombre y la mujer. Expresando nuestro absoluto acuerdo con el principio, no ocultamos nuestra gran inquietud por las dificultades que surgirán cuando se ejerciten estos derechos. Concedidos éstos, sólo el diálogo maduro entre los cónyuges, constituirá alternativa de solución constructiva. Nos interrogamos respecto a si las gentes de nuestro país están preparadas para administrar estos derechos en aras del fortalecimiento de la familia.

Luego en el análisis excluimos el Capitulo III "Régimen Patrimonial del Matrimonio, Sección Primera: Disposiciones Generales", dejándolo para oportunidad distinta.

\section{SEPARACION DE CUERPOS}

Nos referimos en cambio al Capitulo IV: "Decaimiento y Disolución del Vinculo", Sección Primera (Separación de cuerpos).

El ponente ha realizado un excelente trabajo de reordenamiento técnico y coherente, basándose en correcciones al Código Civil de 1936 en esta materia.

Sin embargo el Art. 380 de la ponencia, sobre causas de Separación de Cuerpos, nos ha merecido algunos comentarios, en los Incs. 5 y 9, así como en el párrafo final.

Respecto al Inc. 5 "el abandono malicioso de la casa conyugal por más de dos años continuos", creemos que en aras de la organicidad, debe estar convenientemente seguido por el texto del Art. 384 de la ponencia. La naturaleza del texto del Art. 384 de la ponencia así lo obliga. 
El Art. 384 de la ponencia sostiene que "si uno de los cónyuges abandona maliciosamente la casa conyugal más de una vez y la duración sumada de los períodos de abandono excedieran de dos años, el juez podrá declarar la separación aunque cada período no llegue a dos años".

Apreciando el contenido del numeral citado es conveniente incorporarlo como párrafo segundo del Inc. 5, Art. 380 de la ponencia.

En cuanto al Inc. 9 del Art. 380 , pensamos que es procedente determinar, a fin de que no exista duda, que la condena a que se refiere, tiene relación exclusiva con la comisión de delitos dolosos. Por ello, reformulamos el texto de este Inc. 9 bajo el siguiente tenor: "la condena a pena privativa de la libertad mayor de 2 años impuesta por delito doloso después de la celebración del matrimonio".

Siempre dentro de la tendencia de hacer claro y coherente el Proyecto observamos que, el último párrafo del Art. 380 de la ponencia, no tiene ligazón directa con el Inc. 9 que lo precede. Este párrafo final se refiere a la procedencia de mutuo disenso después de transcurridos dos años desde la celebración del matrimonio. Es conveniente la autonomización de tal párrafo en un artículo propio.

El Art. 381 de la ponencia, inspirado en el Art. 248 del Código Civil de 1936, se refiere a los titulares de la acción de separación. La acción corresponde a los cónyuges, pero si alguno de ellos deviene en incapaz a causa de enfermedad mental o ausencia, puede ser representado por sus ascendientes.

Formulado asi el precepto, observamos que el incapaz sin ascendientes, teniendo derecho a accionar, carece de representante competente. En concordancia con el Art. 248 del Código Civil de 1936, consideramos válida la alternativa de concederle a tal incapaz la posibilidad de contar con un curador especial, el que sólo puede demandar la separación de cuerpos. 
El artículo quedaria bajo la siguiente regla:

"La acción de separación corresponde a los cónyuges".

"Si alguno de ellos fuere incapaz de ejercerla, a causa de "enfermedad mental o ausencia, podrá ser representado en "la acción de separación por causal específica por cualquiera "de sus ascendientes. A falta de ascendientes un curador es. "pecial sólo podrá ejercer la acción de separación de los "casados".

Luego merece nuestra atención el Art. 390 de la ponencia. Se refiere a la pensión alimenticia con que deben concurrir los padres entre si y éstos respecto a sus hijos.

La experiencia económica del pais y la realidad de las necesidades humanas, obligan a pensar en propuestas que den al instituto de los alimentos, la dinamicidad que requieren las urgencias de los hombres.

Una porción muy significativa de los demandados por alimentos corresponden al sector ocupacional de trabajadores independientes, cuyos ingresos son tantas veces difícil de verificar. Otra cuota de demandados pertenecen al campo laboral de los dependientes, cuyos ingresos si son verificables. Estos últimos ingresos están sujetos a aumentos periodicos. Sugerimos que en las sentencias sobre juicios de alimentos, no se estime el pago de cantidades fijas en soles, sino el abono de porcentajes del sueldo real del trabajador, pago éste que debe ser abonado directamente por el empleador bajo responsabilidad.

Esta mecánica permitiría al demandado enfrentar las urgencias del alza de costo de vida, y lo situaria en la posibilidad de no activar repetidas veces juicios de aumento de pensión alimenticia.

Esta sugerencia, deberia tenerse en cuenta, también para el análisis de la sección correspondiente a "Alimentos". En dicha sección debería aparecer la regla que ordene este principio para normar el pago de alimentos. 


\section{DIVORCIO}

Luego en la Sección Segunda, sobre "Divorcio", nos llama a comentario el Art. 398 de la ponencia. El artículo se refiere a la relación alimentaria entre los ex-cónyuges.

El artículo de la ponencia está compuesto por seis párrafos. En los párrafos 2 y 3 percibimos una misma tendencia. Sancionan con el pago de alimentos al cónyuge culpable. Es la culpa la que se sanciona.

Asi, el párrafo segundo del Art. 398 de la ponencia afirma:

"Sin embargo, si se declara el divorcio por culpa del marido "y la mujer no tiene bienes propios ni gananciales suficien"tes, ni está acostumbrada a subvenir a sus necesidades con "el producto de su trabajo lucrativo, el juez asignará en fa"vor de ella una pensión alimentaria que no exceda de la "tercera parte de la renta de aquél".

El tercer párrafo del mismo numeral 398 de la ponencia afirma que:

"Lo dispuesto en el párrafo anterior regirá a favor del ma"rido en caso de declararse el divorcio por culpa de la mujer

"si ésta tuviera rentas suficientes y el marido fuere pobre e "imposibilitado para el trabajo".

Los dos párrafos del Art. 398, segundo y tercero, sancionan con el pago de alimentos al cónyuge culpable.

Sin embargo el párrafo quinto del mismo numeral 398, rompe con el principio de sancionar alimentariamente, al cónyuge que con su culpa determinó el naufragio del matrimonio.

Dice tal párrafo quinto:

"El ex-cónyuge indigente debe ser socorrido por su consorte, "aunque hubiese dado motivos para el divorcio". 
Este párrafo se inspira en el Art. 263 del Código Civil de 1936.

Como acto humanitario la medida es justificada. Mas, disuelto el vínculo marital, no encontramos convincente que el cónyuge ofendido, deba concurrir, tal vez de por vida, al mantenimiento alimentario de quien provocó el sucumbamiento del matrimonio. A él, al cónyuge ofendido, más bien hay que situarlo en actitud plena de que pueda realizar su vida, alimentando debidamente a su prole, y también adecuadamente a su nuevo consorte para quien en modo alguno deben quedar resabios de la presencia del mal cónyuge anterior.

Por esta consideración nos pronunciamos por la supresión del párrafo quinto del Art. 390 de la ponencia.

Dificultad en la disposición del tiempo, frustra ahora, el anhelo de pronunciarnos con comentarios cuasi-elaborados, en los ámbitos del Régimen Patrimonial, Adopción y Relación paternofilial, Sección hasta la que llega la enseñanza que impartimos en aulas universitarias sobre el curso Derecho de Familia I.

Sin embargo, antes de concluir, resulta crucial y necesario, oportuno, repetir aquí, como parte de este informe, el fundamento de nuestra oposición, a la propuesta de nueva causal de divorcio ("divorcio por el mérito del abandono de hecho"), asunto que se debate en el seno de la Comisión Revisora.

Advertimos que nuestra oposición a la causal sugerida, no implica negativa alguna a discutir con rigor otra u otras sugerencias en el campo de la causalidad del divorcio. Empero, la sugerida, la advertimos reñida con preceptos juridicos, morales y sociales.

He aquí un esbozo de mis razones:

A raíz de la promulgación de la Ley 8305 , Código Civil vigente en el Perú, desde el 14 de noviembre de 1936, son causas de divorcio absoluto las siguientes: 
a) El adulterio;

b) La sevicia;

c) El atentado contra la vida del cónyuge:

d) La injuria grave;

e) El abandono malicioso de la casa conyugal, siempre que haya durado más de dos años continuos;

f) La conducta deshonrosa que haga insoportable la vida común;

g) El uso habitual e injustificado de substancias estupefacientes;

h) La enfermedad venérea grave contraida después de la celebración del matrimonio;

i) La condena por delito a una pena privativa de la libertad. mayor de dos años, impuesta después de la celebración del matrimonio.

Este es el sistema que ha imperado durante 46 años en nues tro pais. El doctor Héctor Cornejo Chávez, por si declarado antidivorcista, autor de la propuesta del Libro de Familia del Proyecto de Código Civil peruano, salvo dos precisiones prácticas en las causas e) y g) antedichas (la primera permitiendo que periodos de abandono menores de dos años puedan acumularse para efectos de invocar la causal, y la segunda incorporando el uso de drogas alucinógenas como razón de divorcio), ha repetido los motivos de disolución del vínculo preexistentes en el Código Civil peruano de 1936.

Sin embargo, al interior de la Comisión Revisora del Proyecto de Código Civil, ha surgido la iniciativa de ampliar en una más las causas de divorcio en el Perú.

El alcance (no la redacción) de la nueva regla jurídica seria el siguiente:

- Si los cónyuges se separan de hecho, por un periodo no menor de cinco años continuos, el juez deberá declarar el divorcio absoluto, a solicitud de cualquiera de los cónyuges.

Esta radical innovación, colocará al Perú en una suerte de pionero ensayista de una fórmula que ha sido experimentada en nuestro continente excepcionalmente en la vecina República del 
Ecuador, país divorcista en América desde la ley del 2 de octubre de 1902. Art. 21, Inc. 4, y cuyos resultados sociales aqui se desconocen (1).

Es cierto, que en esta hora de la historia, resulta manifiesto, encontrarnos frente a una corriente divorcista en el universo jurídico, sólo alterada por los matices que sellan las caracteristicas de cada legislación. Que son incontables quienes piensan como el ex-Presidente de Chile, don Arturo Alessandri, quien en pleno ejercicio de su mandato, e impulsando el divorcio en su patria afirmaba: "Considero que el matrimonio indisoluble es un crimen. Condenar a una criatura a eterna soledad sentimental por una equivocación o desgracia de la vida, es ir contra las leyes de la naturaleza" (2), sin que sus dramáticas palabras hayan variado para nada, hasta la fecha, el sistema juridico antidivorcista chileno.

Es probable que el divorcio absoluto constituya un mal necesario. La complejidad de la conducta humana y de las circunstancias propias de la vida, parecen aconsejar que, en efecto, hay dolorosos casos que no tienen más ruta resolutiva que la del divorcio absoluto. Una porción muy significativa de juristas en el universo sostienen aquello. El doctor Héctor Cornejo Chávez, notable especialista en el ámbito del Derecho de la Familia, público antidivorcista, tampoco ha osado contradecir la corriente establecida por el Código Civil de 1936.

El debate de ayer, sigue teniendo hoy la misma connotación.

De un lado quienes sostienen con rotundidad, que el matrimonio alberga en sus mismas entrañas un principio $y$ un fin de interés público; que al lado de sus superiores valores (perpetuación de la especie, educación de la prole y asistencia reciproca), apunta a la creación y a la consolidación de una sociedad en or-

(1) Actas de las Sesiones de la Comisión Reformadora del Código Civil peruano, 2\% fasciculo, Sesión 52, de 31 de octubre de 1923, página 134. Informe de Leyes de Divorcio en los Paises Americanos, Secretaria General, OEA, Washington, D. C., 1974, páginas 19 y 20.

(2) Actas de las Sesiones de la Comisión Reformadora del Código Civil peruano, 2 \% fascículo. Sesión 52, de 31 de octubre de 1923, página 138. 
den: que no podrá hablarse de orden, en tanto no haya un adecuado control de las relaciones humanas, y un firme e irreductible respeto a los derechos y a los deberes asumidos a partir de la concreción del matrimonio.

Al frente, en cambio, se encuentran los que podriamos llamar privatistas. Se hallan motivados por una búsqueda individualista de la felicidad. Se animan por una suerte de eudemonismo. Aspiran a su propio interés y a su satisfacción personal, aún cuando seria atrevido afirmar que no aspiran a la felicidad de otros.

Es esta la antigua polémica sobre el divorcio en la que tanto incide la concepción doctrinaria del universo, la formación del alma, y la educación del instinto. Es un problema axiológico.

Mas no hay duda que para algún o algunos legisladores en la Comisión Revisora del Proyecto del Código Civil, hasta hoy no hemos avanzado suficiente en el Perú en materia de causalidad para el divorcio, y se sugiere la fórmula antes expuesta.

"Nadie puede invocar hecho propio", ha sido y es un antiguo precepto doctrinario que reza desde tiempo en nuestra legislación. Supone que en materia de divorcio, el cónyuge que incurre en alguna(s) de las causales agraviantes, no puede plantear judicialmente tal hecho para solicitar la disolución del vinculo. Esta es potestad del consorte agraviado, el cual de acuerdo a su propia concepción de las circunstancias, podrá actuar desde el perdón conciliatorio y generoso hasta la radićal decisión de poner fin a la vida marital. Jamás se ha concebido en nuestra tradición jurídica, y en una porción muy significativa del universo jurídico, conceder al cónyuge ofensor, la facultad disolutoria del matrimonio en el instante en que convenga a sus particulares intereses personales.

Constituye ello una suerte de estremecedor beneficio al cónyuge libertino; auspiciará psicológicamente los acercamientos clandestinos en la expectativa de convertirlos en futuro matrimonio. Tal causalidad introducida como motivo de divorcio, harả perder por completo a esta institución el carácter de docencia moral 
que pudiera atribuirsele. El agraviante no sólo agraviará a su cónyuge y a su familia, agraviará a la soledad, a su orden, lo socavará, e ingresaremos a una pendiente de resultados impredecibles.

La propuesta surgida al interior de la Comisión Revisora del Proyecto del Código Civil, convierte al matrimonio en un acto contractual casi inexistente y ciertamente desconoce, en absoluto, el carácter de institución del matrimonio. La propuesta sugiere que la simple voluntad unilateral de una de las partes que actuó en el contrato (como acto) matrimonial, puede poner fin al matrimonio. No interesa el matrimonio como estado; no interesan los efectos sociales y morales de la ruptura; ni siquiera interesa el divorcio como docencia moral, pues quien ofendió a la familia, puede aún burlarla en los estrados judiciales, mofándose de ella, invocando su agravio como razón suficiente. $Y$ se propone que el Estado cautele tamaña afrenta. Aün en las resciciones contractuales más efimeras, en las de menor trascendencia o repercusión, por el mérito de su bilateralidad, de haber actuado dos partes, se requiere que ellos en conjunto transijan respecto a la solución adecuada. En la propuesta no, pese a que se trata de la convención más importante que pueden suscribir dos seres humanos, que por su libre voluntad unen sus vidas en el juramento de la fidelidad, de la cohabitación y de la asistencia reciproca. Pese a que se trata de la familia, de la auténtica célula fundamental de la sociedad, la convención puede ser rota arbitraria y unilateralmente, aún por el cónyuge agraviante. Nadie imagina ahora, entre nosotros, un matrimonio validado por la simple voluntad de uno de los contrayentes; sería ello calificado probablemente como una monstruosidad. Pero nada de extraño, de irregular, se halla en la ruptura del vinculo matrimonial por el mérito de una simple voluntad unilateral.

Para esta posición la teoría del matrimonio-institución no tiene preferencialidad. La relación matrimonial, puede ser interrumpida o concluida ad libitum. Los deberes y los derechos matrimoniales, las relaciones y responsabilidades propias de él, son una suerte de simplista negocio jurídico, que puede ser resuelto de acuerdo a la arbitraria orientación de una voluntad. 
¿Es a este tipo de formulación y propuesta, a que se refiere la flamante Constitución del Estado, cuando declara que "El Estado protege el matrimonio y la familia como sociedad natural e institución fundamental de la nación..." (Art. 5)?

Una rápida revisión de la relación de causas de divorcio que nuestro derecho ampara, nos llevará con facilidad a la comprobación de que quienes invocan el divorcio, lo hacen argumentando uno o varios motivos. Pero una es, cruda y rotunda, tantas veces, la capital razón de su proceder, la presencia de una tercera persona extraña al matrimonio. Los magistrados, encargados de juzgar incontables casos de esta naturaleza, tal vez, puedan añadir algunas palabras a lo aqui expresado. $Y$ si este aserto se confirma, como pareceria manifiesto, la propuesta que se sugiere ¿no se constituirá en una suerte de vestibulo del amor libre?

Habrá quienes afirmen que la ponencia es sana; que concluido el amor no hay ya matrimonio; y que resulta imprescindible regularizar toda unión clandestina. Mas legalizar estos fenómenos no conduce a eliminarlos, ni resulta politica sana para la educación social y moral de un pueblo. Con tan sencillo expediente, fácil será estar jamás en falta, pues frente a la ley que nos dice que un hecho es malo, bastará invocar otra que nos diga que ese mismo hecho es bueno. No se trata de disfrazar las realidades; se trata de revisar con el más profundo criterio de conciencia, la responsabilidad ética que entraña un matrimonio.

Admitida esta causal, el divorcio romperá el marco dentro del cual pretendió encerrársele, y avanzará en nuestra sociedad como torbellino, socavando el matrimonio hasta desnaturalizarlo.

La ola desencadenada de la pasión humana es dificil de controlar cuando se es imprudente; es probable que si la Comisión Revisora rechaza la causal propuesta, se frustren algunas vidas. pero concedida, se pondrá en la familia y en la sociedad un factor de descomposición tan terrible que, tal vez no nos permita, a quienes lo toleramos, soportar mañana el juicio de la historia.

Ocurre que la simple existencia de una causal de naturaleza tolerante y liberal como la que se comenta, estimulará inmaduros, 
irreflexivos e impremeditados matrimonios, de quienes van al acto civil, inciertos y confusos, pero seguros de que transcurrido un lapso, tienen a su antojo abierta la alternativa de concluir con el vinculo matrimonial, en el instante en que lo resuelvan.

En el ámbito social la propuesta parece no adaptarse al concepto de realización integral de la persona humana.

El pais se encuentra en trance remoto, de resolver el problema de sus gentes, dieciocho o más millones de habitantes. Más aún, si se trata de activar su superpoblación, mediante ensayos polémicos. El imperio del instituto sexual es extraordinario, y a veces desbordante. El esposo que ha obtenido el beneficio de la partenidad, también lo intentará, sin muchas dudas en su segunda unión marital. Los hijos de un sólo padre se multiplicarán. El varón será desde ese instante socorro de dos hogares. A ambos quedará ligado, por moral y por ley. Columna de sustento para la educación, la alimentación, la salud, el vestido, el techo, recreo, ¿será capaz de cumplir con dignidad, y en eficiencia, la tarea por sí titánica que demanda el cuidado de un solo hogar?

El Censo Nacional de 1972, estableció que el $44 \%$ de la población eran menores, de 0 a 15 años (3). Cuarenticuatro por ciento que requiere de una justa dedicación de sus padres, y de una familia organizada.

La tasa de fecundidad en el Perú, en un siglo, sólo descendió 6.0 (de 43.6 a 37.6 por mil) (4).

Para 1990, un Perú de 23'322.9 habitantes, albergará a $41 \%$ de menores de 0 a 14 años. O lo que es igual, 9'519.4 de niños (5). Más del cuarenta por ciento de la población con derecho natural a una familia organizada, a un padre y a una madre, a un orden, $y$ a un destino digno como personas humanas.

(3) "El Niño en el Perü", Instituto Nacional de Estadística y UNICEF, 1978, página 10.

(4) "El Niño en el Perú", Instituto Nacional de Estadistica y UNICEF, 1978, página 19.

(5) "El Niño en el Perü", Instituto Nacional de Estadística y UNICEF, 1978, páginas 11 y 16. 
La causal sugerida al interior de la Comisión Revisora del Proyecto del Código Civil, reclama de mucha madurez para su lícito ejercicio. De mucha responsabilidad, que sólo se engendra por la educación y sus valores. De extraordinario grado de preparación integral, para marcar con atinado valor (axiológico), el equilibrio de una decisión humana. $i$ Es el caso del hombre peruano? Una muestra del $5 \%$ de la población nacional, para padres de menores de 0 a 15 años, recogida del Censo de Población y Vivienda de 1972 nos dice que el $83.8 \%$ de padres no concluyeron siquiera la educación primaria (6), y aún cuando hay otras alternativas indudables de formación iquién podria desconocer la trascendencia excepcional de la escuela?

En un pais marcado demográficamente con el sello de la niñez, por qué entregarla, sola e indefensa, al albedrio de un modelo familiar enfrentado a las pautas morales $y$ a las necesidades sociales. Hoy mismo, sobre esta materia, y ante el Congreso de la República, el diputado Giusti La Rosa, Presidente de la Comisión de Familia, a próposito del problema nutricional, ha declarado ante los legisladores que dos millones de niños se encuentran absolutamente abandonados, deambulando en nuestra sociedad.

Es fundamental, tomar en cuenta toda esta exposición de motivos, para previo análisis, decidir sobre ella.

(6) "El Niño en el Perü", Instituto Nacional de Estadistica y UNICEF, 1978, página 38. 